\title{
A study of ECG pattern, cardiac structural abnormalities and familial tendency in patients with early repolarisation syndrome in South India
}

\author{
K G Madhu, Vijo George, T G Binu, R Ranjith, Subair Kunju, R Baiju, K S Mohanan, \\ R Jayaram, $V$ V Radhakrishnan
}

Department of Cardiology, Government T D Medical College, Alappuzha, Kerala, India

\section{Correspondence to} Dr KG Madhu, Department of Cardiology, Government T D Medical College, Alappuzha, Kerala 688005, India; drmadhukg@gmail.com

Received 9 September 2014 Revised 11 November 2014 Accepted 20 November 2014

CrossMark

\begin{tabular}{l}
\hline To cite: Madhu KG, \\
George V, Binu TG, et al. \\
Heart Asia 2014;6:167- \\
171. doi:10.1136/heartasia- \\
2014-010575 \\
\hline
\end{tabular}

ABSTRACT

Background Early repolarisation (ER) on ECG, which was initially believed to be benign, has of late been considered otherwise. Brugada syndrome has recently been thought to be an extension of the ER spectrum, and the familial tendency of the ER pattern is being highlighted. With attention being drawn to ER's association with idiopathic ventricular fibrillation (VF), the prognosis and lineage of patients with an ER pattern are under scrutiny. Aims To analyse ER patterns on ECG, their presence in first-degree relatives and their association with structural heart disease. To classify different types of ER and estimate the prevalence of the high-risk notch/slur pattern in the population studied.

Methods We screened all patients presenting to our department from December 2011 to July 2014 for ER patterns. We excluded patients with other causes of ST elevation that mimicked the ER pattern, those aged $<18$ years, and those not willing to participate in the study. A complete physical examination, 12-lead ECG and echocardiography were performed on all study patients. Willing first-degree relatives were screened with a 12-lead ECG. Of the 963 patients with ER that we initially screened, 843 completed the study. A total of 4116 relatives were screened.

Results Of the 843 patients who completed the study, $687(81.5 \%)$ were male and $156(18.5 \%)$ were female. The majority were asymptomatic ( $70.11 \%)$, but had been referred for ECG abnormalities. Fifteen patients with chest pain were inadvertently thrombolysed and were later diagnosed to have ER. Their ER pattern was exaggerated during chest pain, which made this error highly likely. Among the 48 patients who had acute coronary syndrome (ACS), ER pattern was noticed in a different lead than those affected by ACS. Of these, 27 (56.25\%) had ventricular tachycardia/NF during the acute phase. Six patients had electrical storm without evidence of ACS, and all had a global ER pattern with prominent notching/ slurring on baseline ECG. The most common type of ER pattern was type I (lateral leads; 55.87\%). Twenty-one patients had a Brugada pattern. Of all the patients with $E R$, only a third (34.16\%) had the possibly high-risk notched/slurred ECG pattern. The majority (82.92\%) had a structurally normal heart. We found that mitral valve prolapse (MVP), as assessed by $>2 \mathrm{~mm}$ leaflet prolapse from the annulus, was more common in patients with $E R$ (11.39\%). Of the 4116 relatives screened, $2625(63.78 \%)$ had an ER pattern; a quarter of family members had the inferolateral variety and over $60 \%$ of relatives had the lateral variety. We also noticed different ER patterns in the same family.

Conclusions We found that exaggeration of the ER pattern during chest pain may lead to inadvertent thrombolysis. A notched/slurred ER pattern is found in only a third of patients, who need to be grouped separately, as they may constitute a high-risk category. Patients with ER had MVP at a higher prevalence (almost double) than the general population, probably explaining the high incidence of sudden cardiac death associated with MVP. A familial tendency to an ER pattern was found in more than half of first-degree relatives, with different ER patterns, even the Brugada pattern, found in the same family. This may be because Brugada and other ER patterns belong to the same spectrum and may share the same prognosis. Thus we conclude that further studies regarding $E R$, its association with MVP, risk stratification by notched ECG pattern, and familial distribution along with gene analysis are warranted.

\section{BACKGROUND}

Early repolarisation (ER) on ECG was detected as early as $1936^{1}$ and was considered benign for a long time. ${ }^{2-5}$ In 1984 , the malignant nature of ER was first noted ${ }^{6}$ and was confirmed by several studies, ${ }^{7-18}$ including the seminal paper of Haïssaguerre $e t a l^{19}$ on ER's association with idiopathic ventricular fibrillation (VF). Brugada syndrome ${ }^{20}$ has been proposed to be an extension of the ER pattern ${ }^{21}$ and has become an indication for an implantable cardioverter defibrillator. Bearing this fact in mind and considering that ER has a familial tendency, ${ }^{22-26}$ we analysed ECG patterns of patients with ER presenting to our hospital, along with familial tendency to ER and its association with any structural heart disease. We were also inspired by the fact that ER is a current 'hot' topic and not many studies on ER have been reported from this part of the country.

\section{METHODS}

We analysed the ECGs of all patients presenting to the Department of Cardiology, Government T D Medical College Hospital, Alappuzha, Kerala, South India from December 2011 to July 2014 for ER change. For our study, ER was defined as 'an ECG change characterised by J-point elevation and rapidly upsloping or normal ST segment of $\geq 1 \mathrm{~mm}$ $(0.1 \mathrm{mV})$ above the isoelectric line and present in at least two contiguous leads' and was derived from American Heart Association/American College of Cardiology Foundation/Heart Rhythm Society recommendations for the standardisation and interpretation of the ECG published in Circulation (2009). ${ }^{27}$ Exclusion criteria were $<18$ years of age, not willing to sign the informed consent form, and 


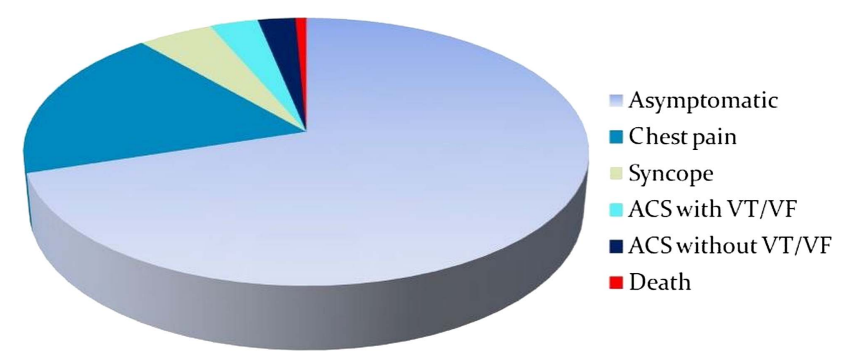

Figure 1 Presentation of patients with early repolarisation. ACS, acute coronary syndrome; VF, ventricular fibrillation; VT, ventricular tachycardia.

other proven causes for ST elevation. Patients whose investigations could not be completed were also excluded. The majority of patients were referrals from other departments, especially the Department of Anaesthesia, for ECG abnormalities. Of the 963 patients initially screened, 843 completed all the necessary investigations and gave informed consent. All these patients had a complete physical examination, 12-lead ECG, and echocardiography. Other investigations were performed according to relevance on a case-by-case basis. First-degree relatives also signed an informed consent form and were screened with 12-lead ECG alone. The total number of relatives screened was 4116 . The

Table 1 ECG patterns in patients with early repolarisation

\begin{tabular}{llll}
\hline Lead involved & No of patients $(\mathbf{n}=\mathbf{8 4 3})$ & Percentage & $\mathbf{9 5 \%} \mathrm{Cl}$ \\
\hline Lateral & 471 & 55.87 & 50.06 to 61.68 \\
Inferior & 162 & 19.22 & 14.61 to 23.83 \\
Inferolateral & 141 & 16.73 & 12.37 to 21.09 \\
Global & 6 & 0.71 & -0.27 to 1.69 \\
Other patterns & 63 & 7.47 & 4.4 to 10.54 \\
\hline
\end{tabular}

results were tabulated, and relevant statistical analysis was performed.

\section{RESULTS}

Of the 963 patients recruited, 843 were included in the study; 687 $(81.5 \%)$ were male and $156(18.5 \%)$ were female. The mean age of the study population was 47.3 years for men and 44.7 years for women. The average heart rate was $57 / \mathrm{min}$ for women and $62 / \mathrm{min}$ for men. The vast majority were asymptomatic (70.11\%) and were referred from other departments for ECG abnormalities, mainly detected during preoperative evaluation (figure 1). The next most common presentation was chest pain, the majority of which was atypical pain. Fifteen of these patients were inadvertently thrombolysed and later diagnosed with ER syndrome, as echocardiography, troponin and coronary angiography (CAG) results were negative. We also noted that the ER pattern in these patients was exaggerated during chest pain, which made this error highly likely. Forty-two patients presented with syncope, but neither their history nor ECG or Holter monitor results suggested significant arrhythmias. Forty-eight patients had acute coronary syndrome (ACS) and an ER pattern in a different lead from those affected by ACS. Of these, 27 (56.25\%) had ventricular tachycardia (VT)/VF during the acute phase. However, we did not notice any association between any particular type of ER and VT/VF. Six patients had electrical storm without evidence of ACS as documented by enzyme assay or echocardiography. These patients ultimately died. We convinced the relatives of three such patients to allow an autopsy, which showed a flabby heart without evidence of ACS. All had a global ER pattern with prominent notching/slurring on the baseline ECG.

Among the ECG patterns of ER (table 1), the most common was type I-that is, involving lateral leads (55.87\%). We found 21 patients with a Brugada pattern (all three types in total), which we grouped with other ER patterns, as the sample size was small. We also grouped patients with a notched/slurred ECG pattern (figure 2) separately to determine its relative prevalence in each type of ER (figure 3).

Echocardiography was performed in all patients to detect structural heart disease (table 2). The majority $(82.92 \%$ ) had a structurally normal heart. We found mitral valve prolapse
Figure 2 Examples of notched/ slurred ECG patterns.
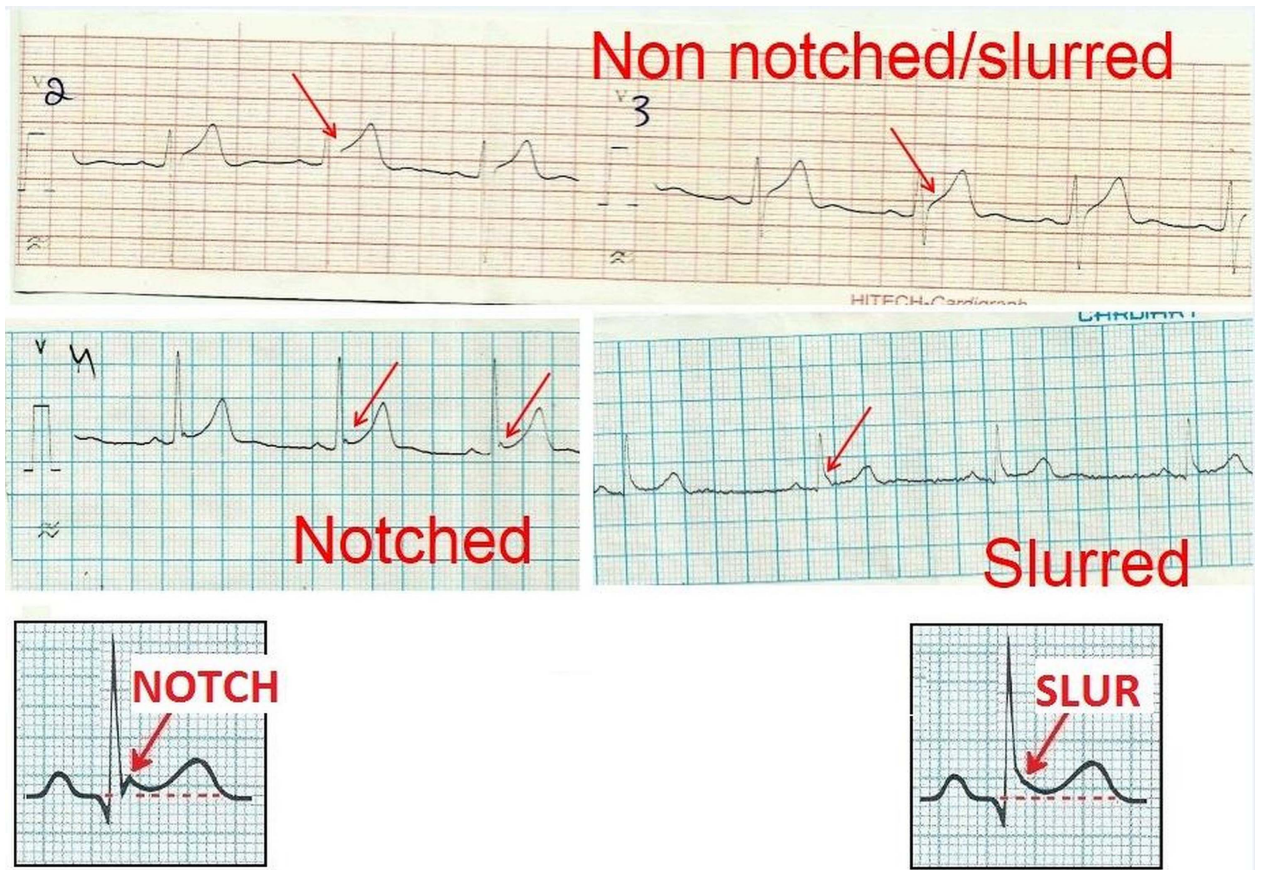


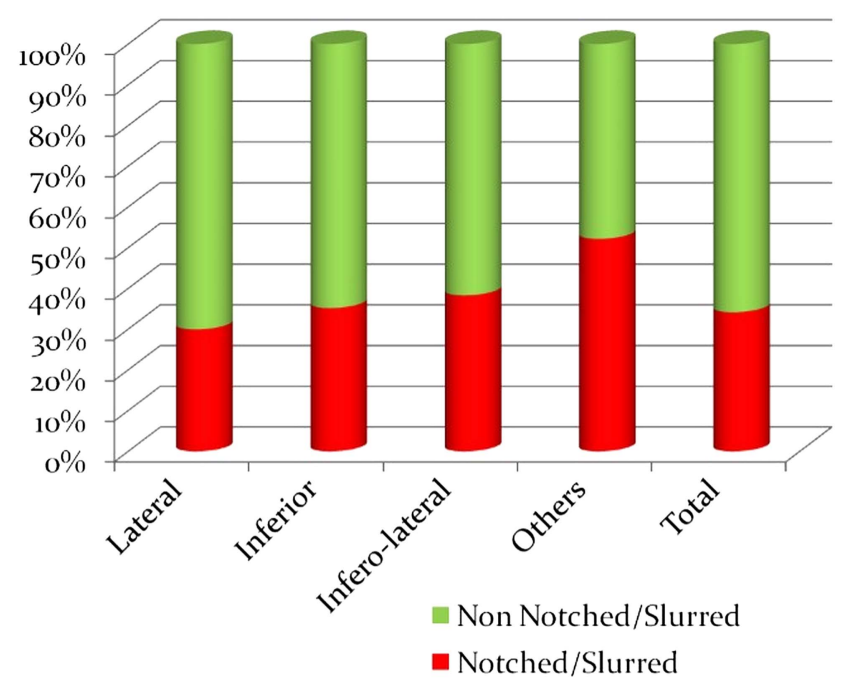

Figure 3 Notched/slurred ECG patterns relative to lead involved.

(MVP), as assessed by $>2 \mathrm{~mm}$ leaflet prolapse from the annulus, to be more common in patients with ER (11.39\%). A total of 117 patients underwent CAG, of which only 48 had significant coronary artery disease (CAD).

To estimate the familial tendency of ER patterns, we screened willing first-degree relatives of the patients with a 12-lead ECG. If at least one of the screened relatives had an ER pattern in any of the leads, it was considered a familial tendency. Of the 4116 relatives screened in total, $2625(63.78 \%)$ had an ER pattern. A quarter of family members with the inferolateral variety and over $60 \%$ of relatives with the lateral variety had familial ER patterns (table 3 and figure 4). We also noted that the ER pattern was not necessarily the same in all family members (table 4). Of the 4116 first-degree relatives screened, 2625 had an ER pattern in one of the leads. The first column in table 4 shows the ER pattern in index cases, and the following columns depict the ER pattern found in relatives of each of the ER patterns in the first column.

\section{DISCUSSION}

ER syndrome is an as yet unexplored subject, and the potential danger associated with ER was only discovered recently. ${ }^{7-18}$ ER has been classified into three types. ${ }^{21}$ Type I has the best prognosis, with ECG changes confined to lateral leads. Type II has moderate risk and has changes confined to inferior or inferolateral leads. Type III has global ER changes and has the worst prognosis. The Brugada pattern is at present considered to be an extension of the ER pattern. ${ }^{21}$ Brugada syndrome has been proven to be arrythmogenic and a definite familial relation has
Table 3 Familial pattern of ER in relatives of index ER patients (cumulative of all patterns)

\begin{tabular}{lcc}
\hline Pattern & Patients with familial pattern & Percentage \\
\hline Lateral & $285 / 471$ & 60.51 \\
Inferior & $84 / 162$ & 51.85 \\
Inferolateral & $36 / 141$ & 25.53 \\
Other patterns & $33 / 69$ & 47.83 \\
Total & $438 / 843$ & 51.96 \\
\hline \multicolumn{2}{l}{ The number of patients whose relatives were screened for ER and at least one of } \\
them had an ER pattern in any of the leads is shown. \\
\multicolumn{2}{l}{ ER, Early repolarisation. }
\end{tabular}

been established, while the three subgroups of ER have no defined management protocols.

Of the ER patients presenting to our department, the majority were asymptomatic, as all surgical patients were screened with an ECG before surgery. Most patients with chest pain had atypical pain, and screening for CAD proved negative in the majority. Fifteen patients were inadvertently thrombolysed, as there was an augmentation of ER changes mimicking ST elevation myocardial infarction during their chest pain. This augmentation just before the onset of arrhythmia is well documented. ${ }^{28-35}$ A total of 117 patients underwent CAG. Only 48 of these patients had significant CAD and were managed accordingly. We did not perform a vasoreactive test to rule out vasospastic angina in any of these patients, as it was not considered essential and hence not cleared by the institutional ethics committee.

We also noticed that it is possible to have both ACS and ER changes on the same ECG but in different leads. Of the 48 patients with ACS, 27 developed VT/VF during ACS. Interestingly, all 27 had a notched/slurred QRS pattern, and 15 of them had ER changes in inferior leads. Many studies that suggested an association of idiopathic VF with ER pattern also found notching on ECGs of affected patients. ${ }^{4} 69111317-192333-35$ This is also true with Brugada syndrome, ${ }^{20}$ where right bundle branch block is associated with ST elevation. The six patients in our study with idiopathic VT/VF also had a global ER pattern with notching of QRS. Thus we categorised patients with a notched ECG pattern separately to determine its relative prevalence and found that fewer than $35 \%$ of the total patients with ER had a notched ECG. Thus, if notching proves to be a reliable indicator of higher risk in patients with ER, the majority of ER patterns will remain benign (65\% in our study). This could again help in risk stratification. ${ }^{17}$

The most common type of ER pattern was type I (confined to lateral leads), and the most common population was young men. This has also been documented in other larger studies. ${ }^{2-5}$ From echocardiography results, we found the majority of

Table 2 Echocardiographic findings in the 843 study patients

\begin{tabular}{|c|c|c|c|c|c|c|c|c|c|}
\hline \multirow[b]{2}{*}{ Echo } & \multicolumn{2}{|c|}{ Male } & \multirow[b]{2}{*}{$95 \% \mathrm{Cl}$} & \multicolumn{2}{|c|}{ Female } & \multirow[b]{2}{*}{$95 \% \mathrm{Cl}$} & \multicolumn{2}{|c|}{ Total } & \multirow[b]{2}{*}{$95 \% \mathrm{Cl}$} \\
\hline & $\mathbf{n}$ & $\%$ & & $\mathbf{n}$ & $\%$ & & $\mathbf{n}$ & $\%$ & \\
\hline Normal & 585 & 85.15 & 80.54 to 89.76 & 114 & 73.08 & 61.02 to 85.14 & 699 & 82.92 & 78.52 to 87.32 \\
\hline MVP & 69 & 10.04 & 6.15 to 13.93 & 27 & 17.31 & 7.03 to 27.59 & 96 & 11.39 & 7.68 to 15.1 \\
\hline RWMA & 21 & 3.06 & 0.83 to 5.29 & 9 & 5.77 & -0.57 to 12.11 & 30 & 3.56 & 1.39 to 5.73 \\
\hline Other valves & 12 & 1.75 & 0.05 to 3.45 & 6 & 3.85 & -1.38 to 9.08 & 18 & 2.14 & 0.45 to 3.83 \\
\hline Total & 687 & & & 156 & & & 843 & & \\
\hline
\end{tabular}




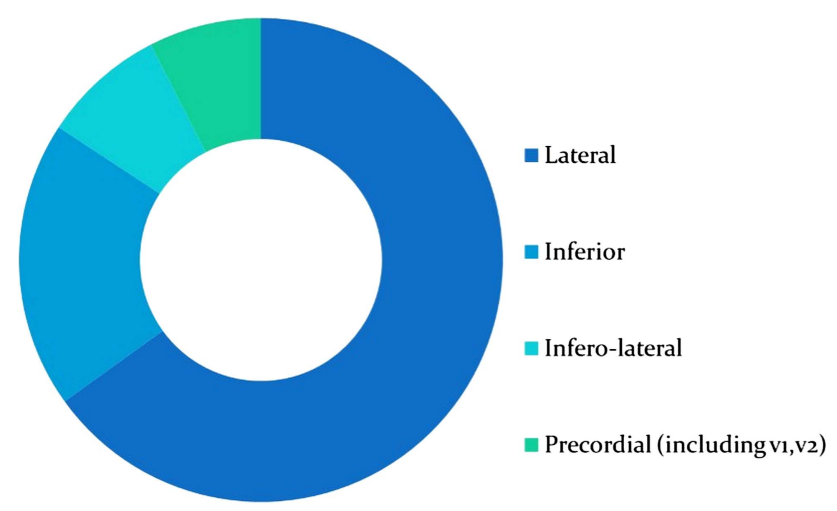

Total $51.96 \%$ had familial pattern

Figure 4 Familial pattern of early repolarisation (cumulative).

patients to have a structurally normal heart, as expected. However, the most interesting finding was that MVP was associated with ER $(11.39 \%)$ at a higher prevalence than in the general population ${ }^{36-37}$ (maximum of 5\%). This probably explains the higher incidence of palpitations and SCD associated with MVP. ${ }^{38-41}$ Further studies in this regard may help to find a definite and clear association.

However, the most interesting part of our study was the magnitude of familial tendency in these patients. Around 51.96\% had an ER pattern running in the family. The most common was a lateral pattern and the least common an inferolateral pattern. Another finding was that the same family can harbour different ER patterns. Patients with a lateral ER pattern on ECG had relatives with an inferior, inferolateral or even a Brugada pattern. This may point to the fact that at least some of the ER patterns may in fact be a continuum of Brugada syndrome and may share the same prognosis. This needs further study.

\section{CONCLUSION}

The shift in concept of ER from being benign to being malignant has revived interest in ER. We noticed that exaggeration of the ER pattern during chest pain in certain patients may mimic ACS, which may lead to inadvertent thrombolysis. These patients usually do not have reciprocal changes in other leads, and echocardiography and troponin investigations will be negative. Patients with a notch/slur ER pattern need to be grouped separately, as they may constitute a high-risk category. Further studies may clarify this, which may help in risk stratification of patients with ER. Another interesting finding was the higher prevalence of MVP (almost double) in patients with ER than in the general population. This probably explains the higher incidence of SCD in MVP. Familial tendency of an ER pattern was found in more than half of the first-degree relatives. The most interesting point was that the ER pattern could vary in the same family, and a Brugada pattern could even be found alongside other patterns. Consequently, the possibility of Brugada and other ER patterns belonging to the same spectrum has to be considered and may even a share similar prognosis. Hence this study lays the foundation for further population-based studies on ER, its association with MVP, risk stratification by notch/slur ECG pattern, genetic screening and familial distribution.

Collaborators Dr Issac V Mamman, Dr Saritha S Nair, Dr MG Divakaran, Dr Gagan Velayudhan, Dr Teffy Jose, Dr Sunitha Viswanathan.

Contributors KGM was the primary investigator and coordinated the whole study, collected the majority of the data, and conducted the analysis. VG, TGB, RR and SK helped with collection of data, while RB, KSM, RJ and VVR helped with analysis. Other collaborators helped KGM with the whole study, as they are part of the department but to a lesser extent than the contributing authors.

\section{Competing interests None.}

Patient consent Obtained.

Ethics approval Institutional Review Board, Government TD Medical College, Alappuzha.

Provenance and peer review Not commissioned; externally peer reviewed.

\section{REFERENCES}

1 Shipley R, Hallaran W. The four lead electrocardiogram in 200 normal men and women. Am Heart J 1936;11:325-45.

2 Mehta MC, Jain AC. Early repolarization on scalar electrocardiogram. Am J Med Sci 1995;309:305-11.

3 Wasserburger RH, Alt WJ. The normal RS-T segment elevation variant. Am J Cardiol 1961;8:184-92

4 Tikkanen JT, Anttonen O, Junttila MJ, et al. Long-term outcome associated with early repolarization on electrocardiography. N Engl J Med 2009;361:2529-37.

5 Yan GX, Lankipalli RS, Burke JF, et al. Ventricular repolarization components on the electrocardiogram cellular basis and clinical significance. J Am Coll Cardiol 2003;42:401-9.

6 Otto CM, Tauxe RV, Cobb LA. Ventricular fibrillation causes sudden death in Southeast Asian immigrants. Ann Intern Med 1984;101:45-7.

7 Gussak I, Antzelevitch C. Early repolarization syndrome: clinical characteristics and possible cellular and ionic mechanisms. J Electrocardiol 2000;33:299-309.

8 Hlaing T, DiMino T, Kowey PR, et al. ECG repolarization waves: their genesis and clinical implications. Ann Noninvasive Electrocardiol 2005;10:211-23.

9 Shu J, Zhu T, Yang L, et al. ST-segment elevation in the early repolarization syndrome, idiopathic ventricular fibrillation, and the Brugada syndrome: cellular and clinical linkage. J Electrocardiol 2005;38(Suppl 4):26-32.

10 Yan GX, Yao QH, Wang DQ, et al. Electrocardiographic J wave and J wave syndromes. Chin J Cardiac Arrhyth 2004;8:360-5.

$11 \mathrm{Nam}$ GB, Ko KH, Kim J, et al. Mode of onset of ventricular fibrillation in patients with early repolarization pattern vs Brugada syndrome. Eur Heart J 2010;31:330-9.

12 Klatsky AL, Oehm R, Cooper RA, et al. The early repolarization normal variant electrocardiogram: correlates and consequences. Am J Med 2003;115:171-7.

13 Rosso R, Kogan E, Belhassen B, et al. J-point elevation in survivors of primary ventricular fibrillation and matched control subjects: incidence and clinical significance. J Am Coll Cardiol 2008;52:1231-8.

14 Abe A, Ikeda T, Tsukada T, et al. Circadian variation of late potentials in idiopathic ventricular fibrillation associated with J waves: insights into alternative pathophysiology and risk stratification. Heart Rhythm 2010;7:675-82.

Table 4 Familial tendency in patients with early repolarisation with respect to lead

\begin{tabular}{|c|c|c|c|c|c|c|c|c|c|}
\hline \multirow[b]{2}{*}{ Lead } & \multicolumn{2}{|c|}{ Lateral } & \multicolumn{2}{|c|}{ Inferior } & \multicolumn{2}{|c|}{ Inferolateral } & \multicolumn{2}{|c|}{ Other } & \multirow[b]{2}{*}{ Total } \\
\hline & $\mathbf{n}$ & $\%$ & $\mathbf{n}$ & $\%$ & $\mathbf{n}$ & $\%$ & $\mathbf{n}$ & $\%$ & \\
\hline Lateral & 909 & 61.84 & 198 & 13.47 & 345 & 23.47 & 18 & 1.22 & 1470 \\
\hline Inferior & 69 & 13.07 & 285 & 53.98 & 174 & 32.95 & 0 & 0 & 528 \\
\hline Inferolateral & 81 & 19.29 & 54 & 12.86 & 276 & 65.71 & 9 & 2.14 & 420 \\
\hline Other & 36 & 17.39 & 27 & 13.04 & 18 & 8.7 & 126 & 60.87 & 207 \\
\hline Total & 1095 & & 564 & & 813 & & 153 & & 2625 \\
\hline
\end{tabular}


15 Antzelevitch C. The Brugada syndrome: ionic basis and arrhythmia mechanisms. J Cardiovasc Electrophysiol 2001;12:268-72.

16 Ghosh S, Cooper DH, Vijayakumar R, et al. Early repolarization associated with sudden death: Insights from noninvasive electrocardiographic imaging (ECGI). Heart Rhythm 2010;7:534-7.

17 Merchant FM, Noseworthy PA, Weiner RB, et al. Ability of terminal QRS notching to distinguish benign from malignant electrocardiographic forms of early repolarization. Am J Cardiol 2009:104:1402-6.

18 Sinner MF, Reinhard W, Muller M, et al. Association of early repolarization pattern on ECG with risk of cardiac and all cause mortality: a population-based prospective cohort study (MONICA/KORA). PLoS Med 2010;7:e1000314.

19 Haïssaguerre M, Derval N, Sacher F. Sudden cardiac arrest associated with early repolarization. N Engl J Med 2008;358:2016-23.

20 Brugada P, Brugada J. Right bundle branch block, persistent ST segment elevation and sudden cardiac death: a distinct clinical and electrocardiographic syndrome. A multicenter report. J Am Coll Cardiol 1992;20:1391-6.

21 Antzelevitch C, Yan GX. J wave syndromes. Heart Rhythm 2010;7:549-58.

22 Reinhard W, Kaess BM, Debiec $R$, et al. Heritability of early repolarization: a population-based study. Circ Cardiovasc Genet 2011;4:134-8.

23 Haissaguerre $\mathrm{M}$, Chatel $\mathrm{S}$, Sacher $\mathrm{F}$, et al. Ventricular fibrillation with prominent early repolarization associated with a rare variant of KCNJ8/KATP channel. J Cardiovasc Electrophysiol 2009;20:93-8.

24 Medeiros-Domingo A, Tan BH, Crotti L, et al. Gain-of function mutation S422L in the KCNJ8- encoded cardiac KATP channel Kir6.1 as a pathogenic substrate for J-wave syndromes. Heart Rhythm 2010;7:1466-71.

25 Burashnikov E, Pfeiffer R, Barajas-Martinez $\mathrm{H}$, et al. Mutations in the cardiac L-type calcium channel associated with inherited J-wave syndromes and sudden cardiac death. Heart Rhythm 2010;7:1872-82.

26 Noseworthy PA, Tikkanen JT, Porthan K, et al. The early repolarization pattern in the general population: clinical correlates and heritability. J Am Coll Cardiol 2011;57:2284-9

27 Rautaharju PM, Surawicz B, Gettes LS, et al. American Heart Association Electrocardiography and Arrhythmias Committee, Council on Clinical Cardiology; American College of Cardiology Foundation; Heart Rhythm Society. AHA/ ACCF/HRS recommendations for the standardization and interpretation of the electrocardiogram: part IV: the ST segment, T and U waves, and the QT interval: a scientific statement from the American Heart Association Electrocardiography and Arrhythmias
Committee, Council on Clinical Cardiology; the American College of Cardiology Foundation; and the Heart Rhythm Society: endorsed by the International Society for Computerized Electrocardiology. Circulation 2009;119:e241-50.

28 Sahara M, Sagara K, Yamashita T, et al. I wave and ST segment elevation in the inferior leads: a latent type of variant Brugada syndrome? Jpn Heart J 2002;43:55-60.

29 Sugao M, Fujiki A, Nishida K, et al. Repolarization dynamics in patients with idiopathic ventricular fibrillation: pharmacological therapy with bepridil and disopyramide. J Cardiovasc Pharmacol 2005;45:545-9.

30 Takeuchi T, Sato N, Kawamura Y, et al. A case of a short coupled variant of torsades de pointes with electrical storm. Pacing Clin Electrophysiol 2003;26:632-6

31 Tsunoda $Y$, Takeishi $Y$, Nozaki N, et al. Presence of intermittent I waves in multiple leads in relation to episode of atrial and ventricular fibrillation. J Electrocardiol 2004;37:311-14

32 Garg A, Finneran W, Feld KF. Familial sudden death associated with a terminal QRS abnormality on surface 12-lead electrocardiogram in the index case. J Cardiovasc Electrophysiol 1998;9:642-7.

33 Nam GB, Kim YH, Antzelevitch C. Augmentation of J waves and electrical storms in patients with early repolarization. N Engl J Med 2008;358:2078-9.

34 Derval N, Simpson CS, Birnie DH, et al. Prevalence and characteristics of early repolarization in the CASPER registry: cardiac arrest survivors with preserve dejection fraction registry. J AmColl Cardiol 2011;58:722-8.

35 Shinohara T, Takahashi N, Saikawa T, et al. Characterization of J wave in a patient with idiopathic ventricular fibrillation. Heart Rhythm 2006;3:1082-4.

36 Freed LA, Benjamin EJ, Levy D, et al. Mitral valve prolapse in the general population. J Am Coll Cardiol 2002;40:1298-304.

37 Theal M, Sleik K, Anand S, et al. Prevalence of mitral valve prolapse in ethnic groups. Can J Cardiol 2004;20:511-15.

38 Barlow JB, Cheng TO. Mitral valve billowing and prolapse. In: Cheng TO, ed. The international textbook of cardiology. New York: Pergamon Press, 1987:497-524

39 Chesler E, Gornick CC. Maladies attributed to myxomatous mitral valve. Circulation 1991;83:328-32.

40 Chesler E, King RA, Edwards JE. The myxomatous mitral valve and sudden death. Circulation 1983;67:632-9.

41 Titus JL, Kelly KL, Edwards JE. Sudden cardiac death: the frequency of its common causes in women versus men. Med J Allina 2000;9(Suppl):24-6. 